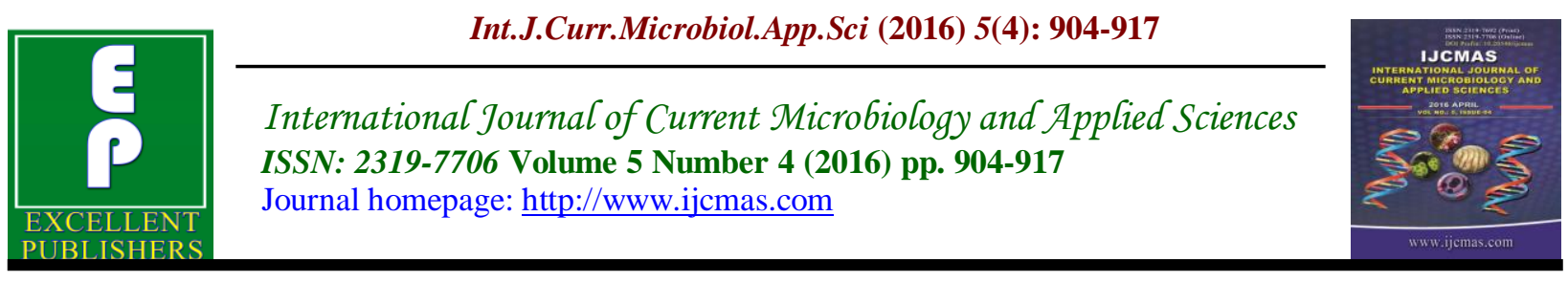

Original Research Article

http://dx.doi.org/10.20546/ijcmas.2016.504.102

\title{
Microaerobic Degradation of Melamine Formaldehyde Resin
}

\author{
B. Umamaheswari ${ }^{1 *}$ and Rama Rajaram ${ }^{2}$ \\ ${ }^{1}$ Environmental Technology Division, CSIR- Central Leather Research Institute, Adyar, \\ Chennai 600 020, Tamil Nadu, India \\ ${ }^{2}$ Retired Chief Scientist, Biochemistry Laboratory, CSIR- Central Leather Research Institute, \\ Chennai 600 020, Tamil Nadu, India \\ *Corresponding author
}

\begin{tabular}{|c|c|}
\hline & A B S T R A C T \\
\hline Keywords & \multirow{4}{*}{$\begin{array}{l}\text { Melamine formaldehyde resin (MFR) has stable aromatic molecular } \\
\text { structures used as retanning agent in leather industry. The bacterial strains } \\
\text { Klebsiella pneumoniae strain CSMB6 and Enterobacter cloacae strain } \\
\text { CSMB2 as consortium was able to degrade MFR in a microaerobic reactor } \\
\text { under optimized conditions. About } 83 \% \text { degradation was obtained with the } \\
\text { residual COD concentration of } 30 \mathrm{mg} / \mathrm{L} \text { at } 48 \mathrm{~h} \text { of incubation along with the } \\
\text { biomass production of } 165 \mathrm{mg} / \mathrm{L} \text { as dry cells. Intermediate metabolites } \\
\text { detected by GCMS, indicates the presence of formic acid, methyl butyl } \\
\text { alcohol, Methoxymethyl formate and 3-Mercapto-3-methyl butyl formate. } \\
\text { The consortium was able to degrade both melamine and formaldehyde } \\
\text { simultaneously utilizing them as sole carbon and energy. }\end{array}$} \\
\hline $\begin{array}{l}\text { Melamine } \\
\text { formaldehyde resin, } \\
\text { Klebsiella } \\
\text { pneumonia, } \\
\text { Enterobacter } \\
\text { cloacae, }\end{array}$ & \\
\hline Article Info & \\
\hline $\begin{array}{l}\text { Accepted: } \\
\text { 24 March } 2016 \\
\text { Available Online: } \\
10 \text { April } 2016\end{array}$ & \\
\hline
\end{tabular}

\section{Introduction}

Melamine formaldehyde resin (MFR) is a hard, thermosetting plastic material, synthesized by condensation of formaldehyde with melamine. MFR is used in retanning of chrome leathers. It gives fullness to leather and provides a tight and uniform grain surface for leather finishing. To make it a water soluble product, it is further sulphated using naphthalene sulphonic acids. Coatings on day-to-day products like plywood and particleboard adhesives, laminated countertops and tabletops, dishwasher-safe tableware, and automotive surface coatings are also made from MFR (Lewis, 2001, Bradley et al., 2005; Kandelbauer and Widsten, 2009).

Melamine resin is nitrogen-rich $(67 \%$ by mass) and hence it is potential nitrogen source during composting (Tian et al., 2012). Melamine is a major component of a colorant (Pigment Yellow 150) and fertilizer (WHO, 2009). Control on melamine contamination in foods (Bhalla et al., 2009) was initiated after an incident of melamine adulteration in infant food (Xin and Stone, 2008), which resulted in renal toxicity. Toxic effects of melamine include 
nephrolithiasis, chronic kidney inflammation, and bladder carcinoma, all of which have been studied in animals (Hau, 2009). MFR releases monomers of both melamine and formaldehyde.

Melamine (1, 3, 5-triazine-2, 4, 6-triamine) is a heterocyclic aromatic compound having a six-membered ring of alternating $\mathrm{C}$ and $\mathrm{N}$ atoms, with three $\mathrm{NH} 2$ groups. It is a member of the s-triazine family and its hydroxyl analogues such as ammeline (4,6diamino-2-hydroxy-1,3,5-triazine),

ammelide (6-amino-2,4-dihydroxy-1,3,5triazine), and cyanuric acid (1,3,5triazinane-2,4,6-trione) were detected in vegetable proteins in contaminated pet foods (Dobson et al., 2008). Formaldehyde is a reactive molecule that contains a carbonyl group which reacts with amines, amides, sulphides, and purines of organic compounds (Vorholt et al., 2000). Formaldehyde may cause nasopharyngeal cancer and possibly leukemia (IARC 2006). Thus the biodegradation of MFR in industrial effluents is necessary due to its threats to human health (Xu et al., 2011). To achieve a longer shelf life and an optimum cross linking density, MFR is synthesized with a high degree of methylolation, etherified with methanol or butanol. Hence, the processed wastewater using MFR generated contains methanol, butanol, urea and ammomium along with formaldehyde and melamine (Glancer, 2001). Among different methodologies for the degradation of formaldehyde, the biological processes are the most economical methods (Di Maiuta et al., 2009). Several bacteria, yeast, and filamentous fungi have been evaluated for the degradation of formaldehyde. Mycobacterium gastri, Rhodococcus sp.,Pseudomonas sp., Acetobacter sp., Paecilomyces sp., Aspergillus sp., and Trichoderma sp. are few examples.(Mirdamadi et al., 2005, Sawada et al., 2006; Shinagawa et al., 2006 Kondo et al., 2008; Yurimoto et al., 2009; Morikawa et al., 2013; Luo, 2013; Bo.X 2015). The possible products of formaldehyde biodegradation are methanol and formic acid (Eiroa 2005). In plants and animals, formaldehyde is metabolized to formate and oxidised to $\mathrm{CO} 2$ by dehydrogenase (Kornbrust, 1983) and catalase enzymes (Halliwell 1974). It has been reported that melamine is recalcitrant to activated sludge, as the induction of enzymes responsible for hydrolytic deamination is poor even after a long period of sludge adaptation (Xu et al., 2013). While many bacteria and fungi are known to degrade melamine and formaldehyde independently, biodegradation studies of MFR are scarce. Although Klebsiella pneumoniae (Ping, 2014 ) and Enterobacter cloacae (Saadoun, 2002) is known for their ability to biodegrade polycyclic aromatic hydrocarbons (PAH), degradation of MFR has not yet been reported by these bacterial strains. Klebsiella terragena strain DRS-1, isolated from sewage sludge enrichments (Shelton et al., 1997) and Micrococcus sp. strain MF-1 isolated from wastewater from an amino plastic plant. (El-Sayed et al., 2006) were reported to have mineralized melamine.

The present investigation was carried out to study the simultaneous removal of formaldehyde and melamine in a lab-scale microaerobic reactor. A consortium that consisted of two isolated bacterial strains was evaluated for the degradation of MFR, as well for finding out if MFR is used as the substrate source for growth by the consortium. The pure chemicals which are intermediate products of MFR were also tested independently for degradation. UVVisible spectrum and GCMS studies were used to identify the intermediate metabolites to construct a degradative pathway for Melamine formaldehyde resin (MFR) 


\section{Materials and Methods}

\section{Chemicals}

The Melamine formaldehyde resin (MFR) was provided by a tannery. Formaldehyde, Melamine, Ammeline, ammelide, cyanuric acid and biuret were purchased from SigmaAldrich, India. The culture medium used for the study is a mineral salt medium containing (g/l): $\mathrm{K}_{2} \mathrm{HPO}_{4}, 1.2 ; \mathrm{KH}_{2} \mathrm{PO}_{4}, 0.3$; $\mathrm{MgCl}_{2} \cdot 7 \mathrm{H}_{2} \mathrm{O}, 0.5 ; \mathrm{NaCl} 1.0 ; \mathrm{CaCl}_{2} \cdot 2 \mathrm{H}_{2} \mathrm{O}$, $0.2 ; \mathrm{FeSO}_{4} \cdot 7 \mathrm{H}_{2} \mathrm{O}, 0.02$; and $10 \mathrm{ml}$ of trace elements. All medium components of analytical grade were procured from E.Merck Mumbai (India).

MFR (ChemSpider ID: 84298) is a hard, thermosetting plastic material made from melamine and formaldehyde by polymerization. Formaldehyde and Melamine (1,3,5-triazine-2,4,6-triamine) are in equal proportion (1:1) in MFR, with molecular formula $\mathrm{C}_{4} \mathrm{H}_{8} \mathrm{~N}_{6} \mathrm{O}$ and average mass of $156.146 \mathrm{Da}$;. Structure of MFR is shown in Fig.1.

\section{Microorganism}

The bacterial strains used in this study were isolated from a phenol degrading microaerobic reactor. The Klebsiella pneumonia strain CSMB6 and the Enterobacter cloacae strain CSMB2 were selected based on their ability to degrade formaldehyde and melamine respectively and also due to their sustainability even after repeated cycles. They are capable of degrading a mixture of heterocyclic compounds in a consortium along with other four isolated strains. For enrichment of MFR and for the degradation studies, a specially designed laboratory scale bioreactor (3.5 l) with the automatic control biosensors to maintain microaerobic condition was used. The working mechanism has been explained elsewhere (Umamaheswari and Rama 2014).

\section{Degradation of MFR}

The concentration of MFR used in the study was $100 \mathrm{mg} / \mathrm{L} \quad(\mathrm{COD}=320 \mathrm{mg} / \mathrm{L})$, corresponding to the concentration present tannery effluents. The isolated strains Klebsiella pneumoniae strain CSMB6 and Enterobacter cloacae strain CSMB2 were added in equal proportions. MFR degradation was monitored by following COD and biomass growth. The degradation of MFR was also monitored by measuring spectral changes in a UV-Visible spectrophotometer (ShimadzuUV2450). Studies were carried out in mineral medium with the MFR as the sole carbon and nitrogen under optimized conditions in a microaerobic reactor (Umamaheswari and Rama 2014). To estimate biomass growth, the centrifuged pellets of the culture were dried at $60^{\circ} \mathrm{C}$ overnight for $24 \mathrm{~h}$, until a constant weight was obtained. Chemical Oxygen Demand (COD) (5220-B) and Nitrogen Ammonia (4500-NH3-C) were estimated using Standard Methods (APHA 2005).

\section{Effect of Different Initial Concentration}

Degradation of MFR by the isolated strain was conducted with initial MFR concentrations of 100, 150, 200 and 250 $\mathrm{mg} / \mathrm{L}$ in a screw capped Erlenmeyer flasks. For this, equal proportion of the cells of Klebsiella pneumoniae strain CSMB6 and Enterobacter cloacae strain CSMB2were inoculated in MSM. A 5\% head space was provided for controlled oxygen and incubated in an orbital shaker with a shaking speed of $50 \mathrm{rpm}$. The percentage degradation was measured at different time intervals.

\section{Effect on Intermediate Metabolites}

Studies on the metabolic versatility was evaluated by inoculating equal proportions 
of Klebsiella pneumoniae strain CSMB6 and Enterobacter cloacae strain CSMB2 to the intermediate metabolites of MFR such as formaldehyde, melamine, Ammeline, ammelide, cyanuric acid and biuret. Concentrations of intermediate metabolites were determined by comparing the calibration with those of authentic standards. The mineral medium was amended with the respective substrates at $50 \mathrm{mg} / \mathrm{L}$. The percentage degradation was estimated by using the formula: Degradation $(\%)=[($ AoA)/Ao]*100, where Ao is the initial concentration of the substrate and $\mathrm{A}$ is the residual concentration after degradation.

\section{Gas Chromatography - Mass Spectrum Analysis}

The ethyl acetate extracts of cell-free medium were analyzed for the degraded metabolites of the MFR by GCMS for mass analysis. The GCMS analysis was carried out using JEOL-GC-mate-II benchtop double-focusing $\mathrm{GC}$ mass spectrometer operating in electron impact ionization (EI) mode. Helium was used as carrier with a flow rate of $25 \mathrm{ml} / \mathrm{min}$. The injector temperature was maintained at $220{ }^{\circ} \mathrm{C}$ (temperature range $70-250{ }^{\circ} \mathrm{C}$ ) and the rate of increase in temperature was set to 15 ${ }^{\circ} \mathrm{C} / \mathrm{min}$. The ethyl acetate extract of the products were dissolved in methanol and subjected to GC/MS analysis. The compounds were identified on the basis of retention time and mass fractions.

\section{Results and Discussion}

\section{Isolation}

The bacterial strain CSMB6 was isolated from a microaerobic reactor, based on its ability to degrade formaldehyde. The strain CSMB6 was identified as Klebsiella pneumoniae strain SDM45. It is a Gramnegative, rod-shaped bacterium, non-motile in nature, encapsulated, lactose-fermenting and facultative anaerobe. It occurs naturally in the soil, and about $30 \%$ of strains can fix nitrogen in anaerobic conditions (Postgate, $\mathbf{J}$ 1998). The strain CSMB2 was identified as Enterobacter cloacae strain SJ6. It is a rodshaped Gram-negative bacterium, facultative anaerobe, bears peritrichous flagella for motility. It is oxidase-negative and catalasepositive. It is generally present in the normal gut flora of many humans.

\section{Biodegradation of MFR}

To evaluate the degradability by the isolated bacterial strains, studies were conducted using MFR in a microaerobic reactor under optimized conditions (DO of $0.9 \mathrm{mg} / \mathrm{L}, \mathrm{pH}$ of 7 and temperature of $30^{\circ} \mathrm{C}$ ) Biodegradation was determined by estimating TOC and monitoring biomass growth in mineral medium containing MFR as the sole carbon and nitrogen source (Fig 2). The results indicated that a maximum of $83 \%$ MFR was degraded with the residual TOC concentration of $30 \mathrm{mg} / \mathrm{L}$ after $48 \mathrm{~h}$ of incubation. Maximum biomass production of $165 \mathrm{mg} / \mathrm{L}$ as dry cells was observed at $36 \mathrm{~h}$ and reduction in biomass noticed from $48 \mathrm{~h}$ may be due to limitation of substrate. Simultaneous production of ammonia was observed from $12 \mathrm{~h}$ of incubation and it continued till $48 \mathrm{~h}$. The release of ammonia is due to the deamination of melamine degradation followed by successive deamination of its secondary metabolites. It is reported that deaminations of melamine and other intermediates occur outside the cytoplasmic membrane (Shelton et al., 1997). Though release of ammonia was continuous during the degradation of MFR, the $\mathrm{pH}$ of the culture was maintained may be due to the accumulation of formic acid by the degradation of formaldehyde. It is reported that formic acid is formed as the intermediate product of formaldehyde by the catalytic reaction of dismutase in bacteria 
and by dehydrogenase in yeast (Glancer, 2001). From the results obtained it is confirmed that the bacterial strains Klebsiella pneumoniae strain CSMB6 and Enterobacter cloacae strainCSMB2, as consortium, utilise MFR as energy for its growth and degrade both formaldehyde and melamine simultaneously. Our results are similar to those observed on degradation of lindane by yeast (Abdul Salam et al., 2013), metabolism of triazines by Arthrobacter aurescens TC1 (Lisa et al., 2002) and Streptomyces strain PS1 (Mirdamadi et al., 2005), where the increase in biomass correlated with the degradation of the respective substrate. When strain CSMB6 was used as the sole inoculant, the degradation of MFR was delayed with a lag period and only $60 \%$ reduction was observed at $48 \mathrm{~h}$.

But when it was co-cultured with the strain $C S M B 2$, the degradation potential was enhanced with absence of lag period. As a mixed culture, they were able to metabolize both melamine and formaldehyde simultaneously, as observed from the reduction in TOC within $48 \mathrm{~h}$. It may be due to the induction of relevant enzymes for the catabolism of MFR and adoption to metabolize new chemical compounds by evolving the needed enzymes (Seffernick, 2001). It has been reported that Klebsiella pneumoniae 99 grows only with ammelide and its lower intermediates utilizing them as sole nitrogen source (Cook, 1987) and the Enterobacter cloacae strain 99 was able to degrade only cyanuric acid to biuret acid (Cheng, 2005). It is reported that stepwise adaptation is needed for pseudo alcaligenes strain(Mirdamadi, 2005) Methylobacterium strains BIP and ROS1 and Marine Microalga Nanno chlorop sisoculata ST-3 Strain, (Chongcharoen, 2005, Yoshida, 2009) for the effective degradation of formaldehyde. The reason may be due to the activity of specific enzymes to catalyze different reactions. The results observed are in agreement with the degradation of melamine formaldehyde resin by Micrococcus $s p$. Strain MF-1. They suggested that the Strain $M F-1$ was able to split melamine moieties and remove formaldehyde prior to melamine degradation (El-Sayed, 2006).

\section{Effect of Initial Substrate Concentration}

The ability of the bacterial strains Klebsiella pneumoniae strain CSMB6 and Enterobacter cloacae strain CSMB2 as consortium to tolerate high MFR concentrations was investigated in the microaerobic reactor at an optimized condition as mentioned earlier. The degradation experiment was carried out with the different initial MFR concentrations as TOC concentration of 400, 800 and 1200 $\mathrm{mg} / \mathrm{L}$ and the TOC removal efficiency are depicted in Fig. 3. Maximum TOC reduction of $75 \%$ was obtained with in $48 \mathrm{~h}$ when TOC of $400 \mathrm{mg} / \mathrm{L}$ concentration of MFR was used. Though the bacterial strains tolerated TOC of $800 \mathrm{mg} / \mathrm{L}$ concentration of MFR, only $16 \%$ degradation was achieved. It may be due to substrate inhibition. Further increasing the concentration to TOC of 1200 $\mathrm{mg} / \mathrm{L}$, inhibition is observed.

\section{Effect on Intermediate Metabolites}

Batch reactor studies were performed to evaluate the degradation of formaldehyde, melamine and its intermediate metabolites by the mixed culture of Klebsiella pneumoniae strain CSMB6 and Enterobacter cloacae strain CSMB2. 10\% of exponential culture was inoculated in minimal medium amended with $(50 \mathrm{mg} / \mathrm{L})$ formaldehyde, melamine and other secondary metabolites independently. The initial dissolved oxygen (DO) concentration observed was $0.9 \mathrm{mg} / \mathrm{L}$. At the end of $48 \mathrm{~h}$, 
DO concentration of $0.02 \mathrm{mg} / \mathrm{L}$ was observed. About 80 to $90 \%$ reduction was observed as TOC measurement after $48 \mathrm{~h}$ of incubation with all the tested intermediate metabolites as shown in Figure 6.4 confirming the degradation of the intermediate metabolites. Metabolism of melamine is based on enzyme catalyzed hydrolytic reactions (Cook, 1987). The amido hydrolase catalyze deamination of nitrogen containing heterocyclic ring substrates (Seibert, 2005, Wackett, 2002). It is suggested that formaldehyde is metabolized either by formaldehyde dehydrogenase or by using a cyclic pathway with ribulose monophosphate cycle (Azachi et al., 1995). Similar to this study, degradation of formaldehyde by different microorganisms (Yamazaki, 2001) and melamine deamination by microbes were reported (Wackett, 2002; Fruchey, 2003; Li, 2009; Seffernick, 2010; Cameron, 2011).

Table.1 Chemical Structure, and Fragmentation Masses of the

Degraded Metabolites of Melamine

\begin{tabular}{|l|l|l|l|l|}
\hline Time & $\begin{array}{l}\text { Retention } \\
\text { time }\end{array}$ & Degraded metabolite & Molecular Weight & \multicolumn{1}{|c|}{$\begin{array}{c}\text { Fragment ion } \\
\text { masses and } \\
\text { Relative intensity } \\
(\%)\end{array}$} \\
\hline $24 \mathrm{~h}$ & \multirow{2}{*}{13.19} & Ammeline & 127 & $127(75 \%)$ \\
\cline { 3 - 5 } & & Methyl Butyl alcohol & 88 & $83(100 \%)$ \\
\cline { 3 - 5 } & Formic acid & 46 & $51(100 \%)$ \\
\hline $36 \mathrm{~h}$ & \multirow{2}{*}{15.08} & cyanuric acid & 129 & $129(65 \%)$ \\
\cline { 3 - 5 } & & 2-Methoxymethyl formate & 90 & $96(100 \%)$ \\
\hline \multirow{3}{*}{$48 \mathrm{~h}$} & \multirow{2}{*}{\begin{tabular}{l} 
Biuret acid \\
\cline { 3 - 5 }
\end{tabular}} & $\begin{array}{l}\text { 3-Mercapto-3-methyl butyl } \\
\text { formate }\end{array}$ & 104 & $102(80 \%)$ \\
\cline { 3 - 5 } & Methyl formate & 60 & $52(100 \%)$ \\
\hline
\end{tabular}

Fig.1 Structure of Melamine Formaldehyde<smiles></smiles>

Melamine

(a) 
Fig.2 Degradation Profile of Melamine Formaldehyde Resin (MFR)

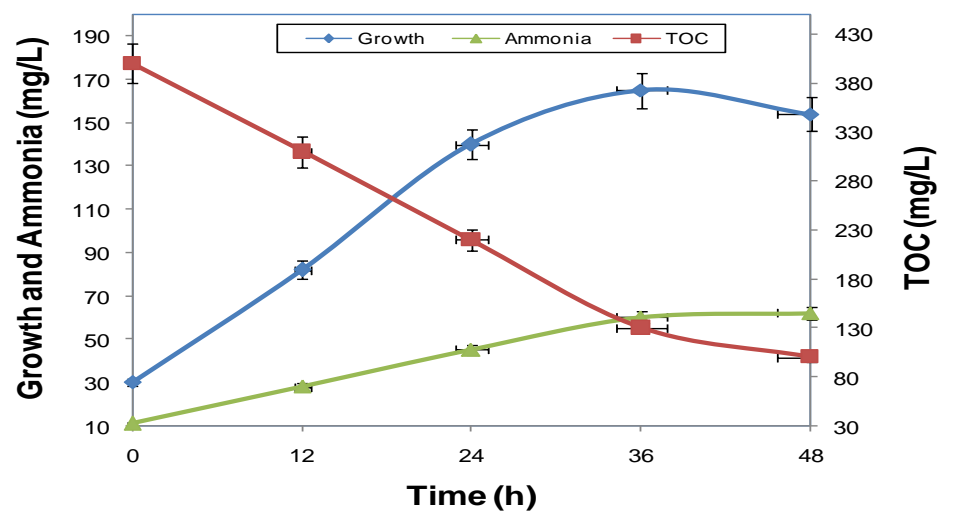

Fig.3 Effect of Initial Concentration of MFR Observed as TOC Removal Efficiency

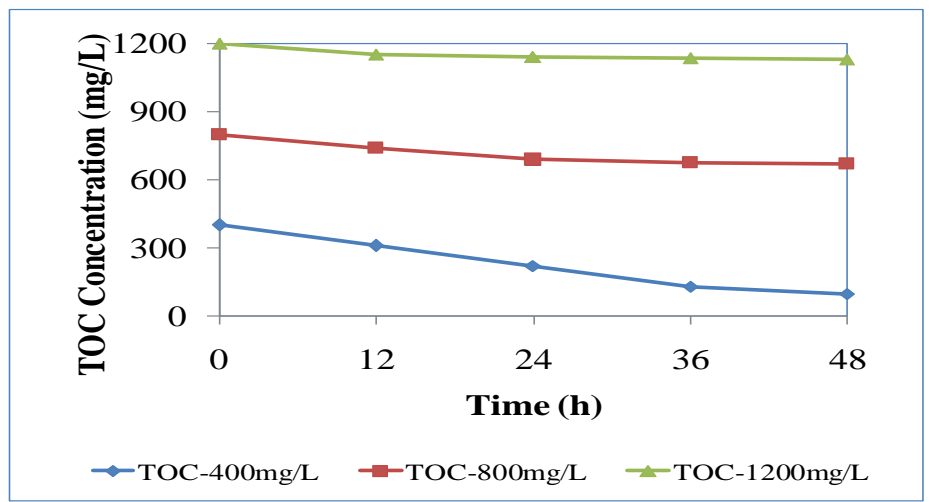

Fig.4 Effect on Intermediary Metabolites of MFR

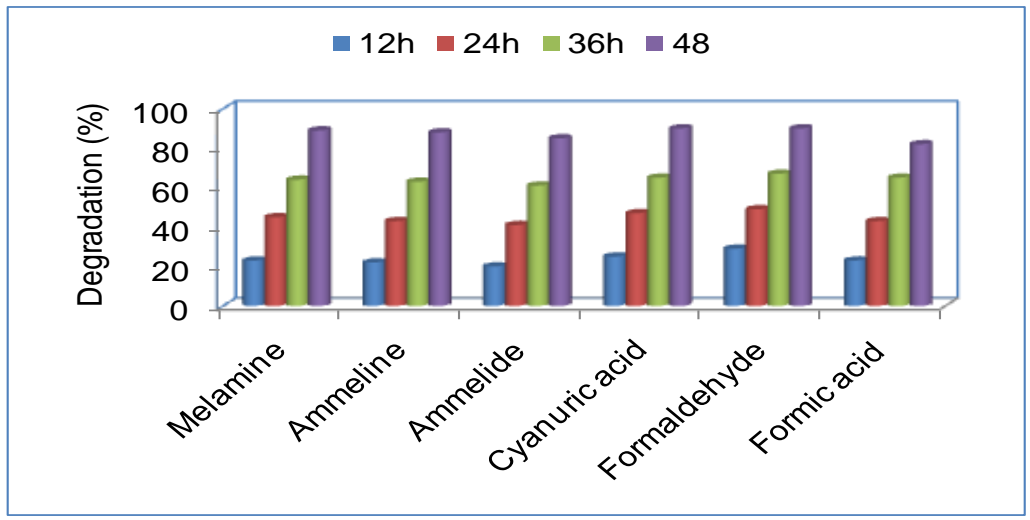


Fig.5 a, b, c Spectrum Showing Degradation of MFR

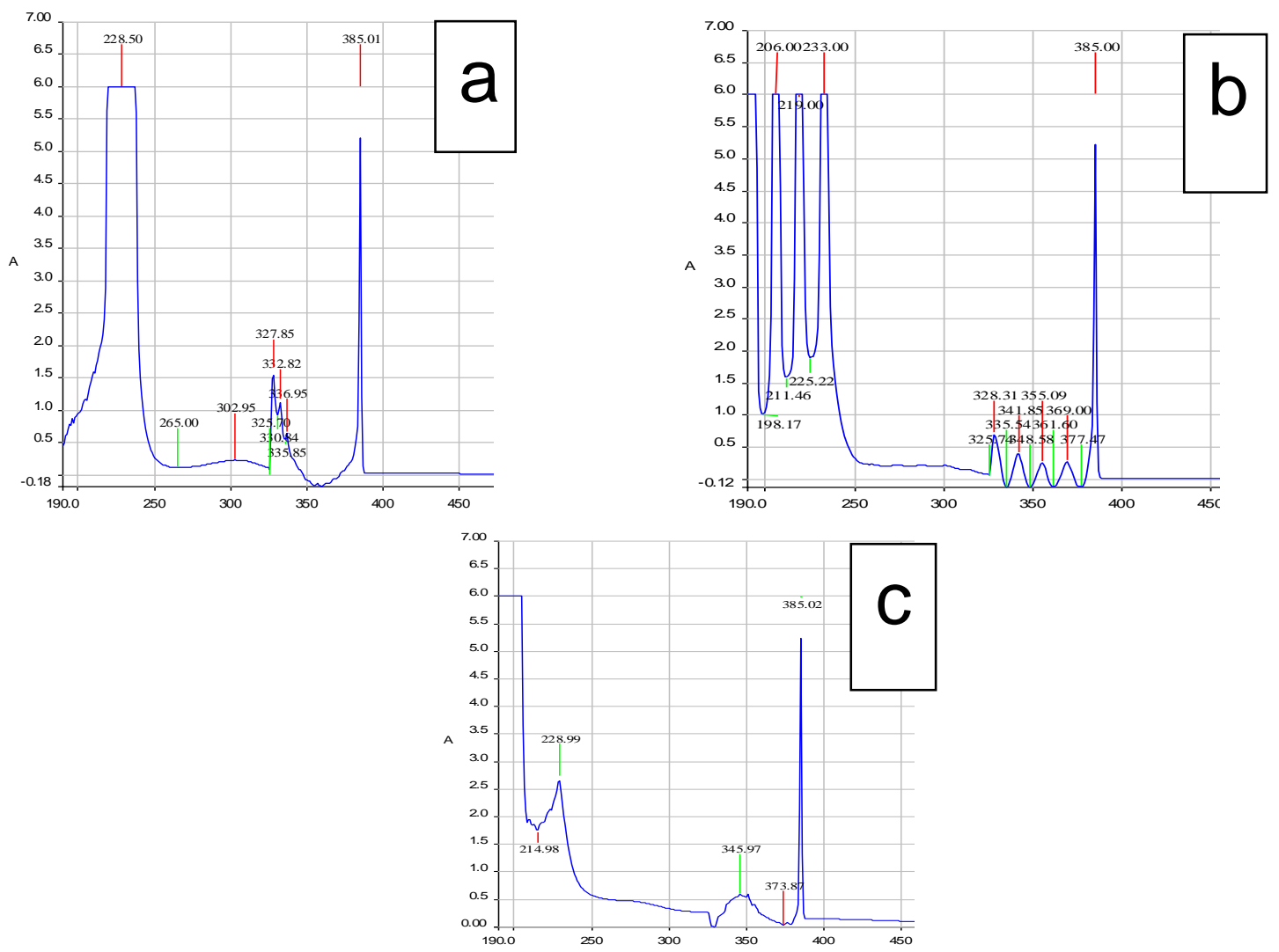

Fig.6 a, b, c GCMS - Degradation Profile of MFR
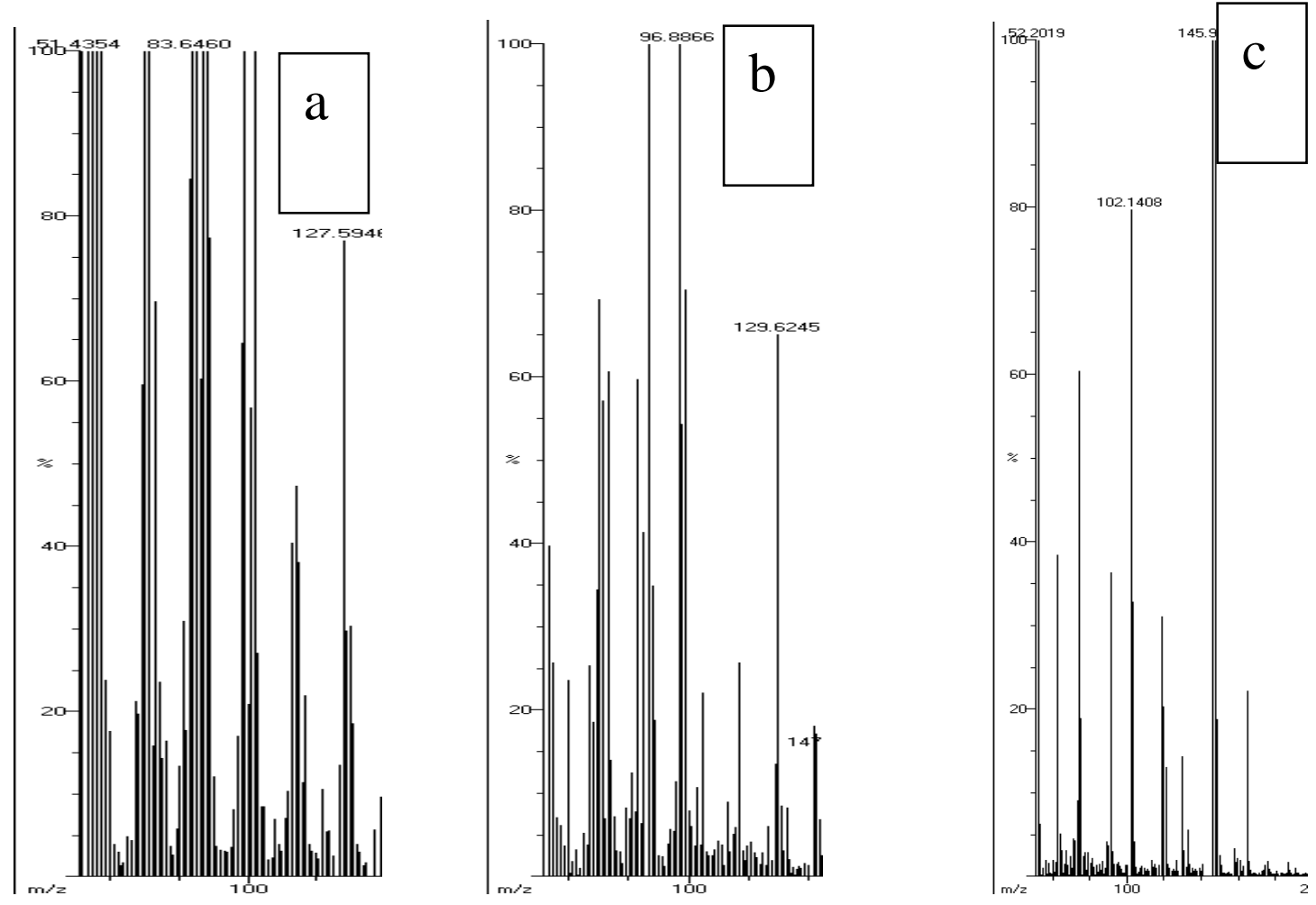
Fig.7 Proposed Microaerobic Degradative Pathway for MFR

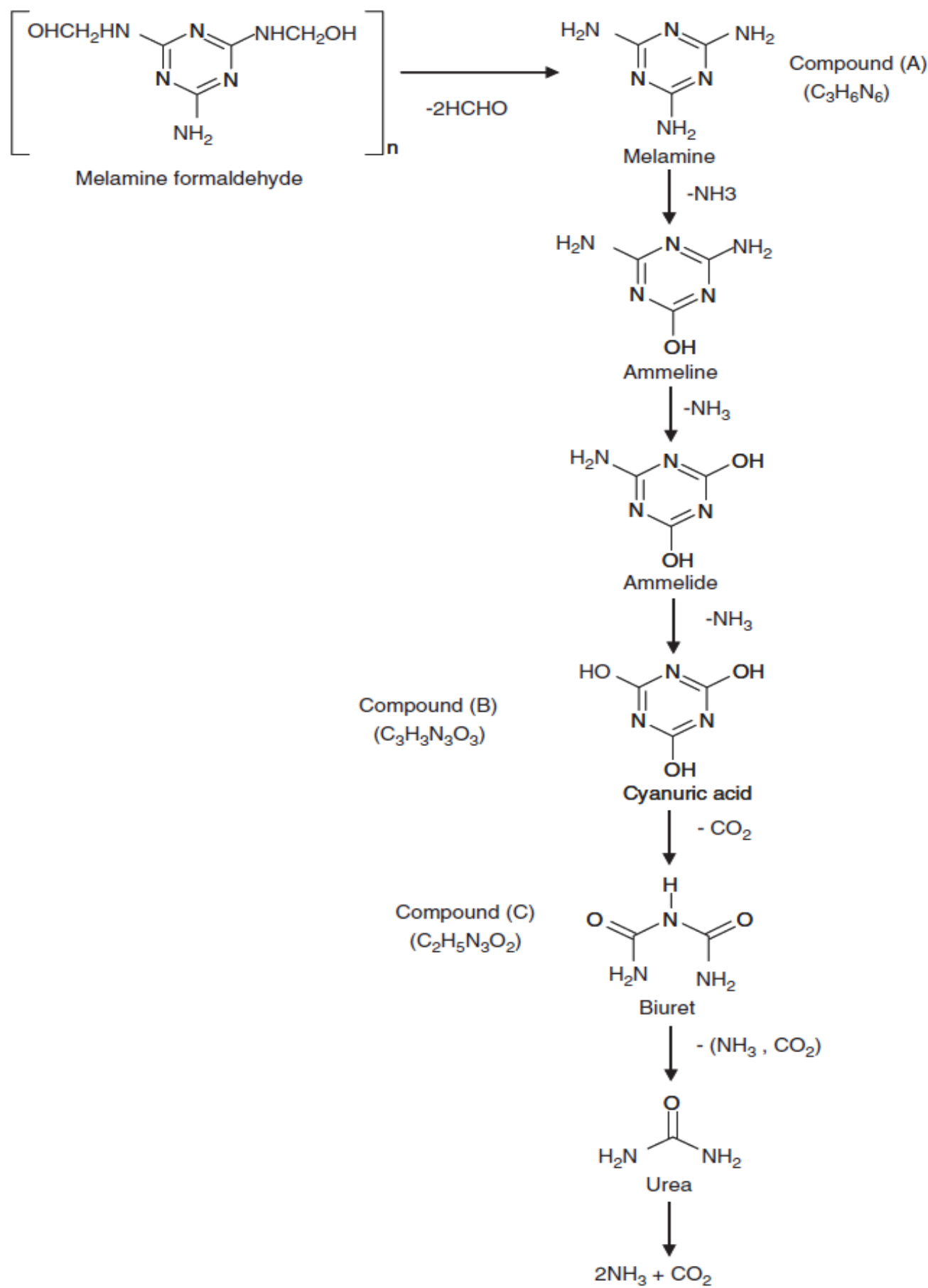

\section{UV-Visible Spectroscopy}

MFR degradation was monitored using UVVis Spectroscopy. The culture supernatant obtained at $0 \mathrm{~h}$ revealed absorption peaks $(\lambda$ max) for MFR and are 385 and $228 \mathrm{~nm}$ (Fig. $5)$. The culture supernatant drawn after $24 \mathrm{~h}$ incubation exhibited a number of new peaks representing oligomeric esters. The disappearance of the peaks at $48 \mathrm{~h}$ might be 
due to the successive deamination of melamine and degradation of formaldehyde to acids and esters. The observation on $48 \mathrm{~h}$ culture sample confirmed the degradation of oligomeric esters representing 70-80\% degradation of MFR. It is reported that since the carbon to nitrogen ratio of melamine is 0.43 , it requires an external carbon source for the catabolism of melamine. Studies by Takagi (2011) revealed that a consortium of three strains ATD6, $C D B 21$, and CSB1 needed ethanol as external carbon source to degrade melamine completely. In the present study, the formaldehyde present in MFR was perhaps used as carbon source by the bacterial strains for the deamination of melamine.

\section{GC-MS Analyses}

GC-MS analyses were carried out to find the metabolites formed during the biodegradation of MFR by the strain CSMB6 and CSMB2. Metabolites were detected by $\mathrm{GC}$ at different retention times of 13 to 17 min. and were identified by comparing the mass with those of authentic standards from the NIST library. The molecular weight (MW) of the intermediates and the fragment ion-mass observed from MFR degradation is given in Table 1 and spectrum is shown in Fig. 6. The intermediates observed after biodegradation of MFR for $24 \mathrm{~h}$ were ammeline, formic acid and methyl butyl alcohol. At 36h, appearance of cyanuric acid and 2-methoxymethyl formate were observed. The supernatant of $48 \mathrm{~h}$ culture revealed the formation of biuret acid, methyl formate and 3-mercapto-3-methyl butyl formate. The results indicated that deamination of melamine may lead to the formation of ammeline. Further deamination of ammeline resulted in cyanuric followed by biuret acid. It is reported that the deamination of melamine proceeds stepwise with the loss of one, two or three amino groups (Bozzi, 2004). Simultaneous degradation of formaldehyde resulted in accumulation of formic acid. Presence of formic acid, methyl butyl alcohol, methoxy methyl formate and 3-mercapto-3-methyl butyl formate confirmed the degradation of MFR which ultimately ends with the release of ammonia and $\mathrm{CO} 2$.

\section{MFR Biodegradation Pathway}

Based on the evaluation studies under microaerobic condition on MFR by the consortium of the two isolated bacterial strains CSMB6 and CSMB2, a biodegradation pathway is proposed as shown in Fig.7. The UV-Visible spectrum and GCMS results indicated the simultaneous biodegradation of formaldehyde and melamine, the main components in MFR. It also suggested that successive deamination of melamine resulted in the formation of cyanuric acid. Decarboxylation of cyanuric may lead to the accumulation of biuret acid with the release of ammonia. It is presumed that the methylol group of MFR (formed by an addition reaction of formaldehyde with amino group of melamine) on degradation was transformed to carboxylic acids and alcohols resulting in oligomeric esters with a release of $\mathrm{CO} 2$.

In conclusion, Melamine formaldehyde resin (MFR) possessing polymeric aromatic molecular structures are highly stable and hence highly resistant to biodegradation. MFR is one of the retanning agents used in leather industry. The ability of the bacterial strains Klebsiella pneumoniae strain CSMB6 and Enterobacter cloacae strain CSMB2 as a consortium for degradation of MFR concentration of $100 \mathrm{mg} / \mathrm{L}$ in a microaerobic reactor under optimized conditions was studied. The results obtained confirm the degradation of MFR for the TOC 
concentration of $400 \mathrm{mg} / \mathrm{L}$, with the residual TOC concentration of $100 \mathrm{mg} / \mathrm{L}$ and biomass (dry cells) production of $165 \mathrm{mg} / \mathrm{L}$ after $48 \mathrm{~h}$ of incubation. Degradation of MFR with corresponding growth proves the utilization of MFR as sole carbon and nitrogen by the isolated strains. When tested for the inhibitory concentration of MFR, above $300 \mathrm{mg} / \mathrm{L}$ was found out to be inhibitory corresponding to TOC content of $800 \mathrm{mg} / \mathrm{L} . \mathrm{UV}-\mathrm{V}$ is spectrum of the culture filtrate after $48 \mathrm{~h}$ confirmed the degradation of oligomeric esters representing 70-80\% degradation of MFR. Metabolites detected in the culture supernatant by GC-MS indicated the presence of formic acid, methyl butyl alcohol, methoxy methyl formate and 3mercapto-3-methyl butyl formate, which confirmed the degradation of MFR. The significance of the present study is that the consortium consisting of Klebsiella pneumoniae strain CSMB6 and Enterobacter cloacae strain CSMB2 was able to degrade both melamine and formaldehyde simultaneously within $48 \mathrm{~h}$, utilizing them as sole carbon and nitrogen, which may be due to their adoption to the pollutants present in leather industrial wastewater. So the consortium of CSMB6 and CSMB2 may be used in the bioremediation of MFR contaminated site.

\section{Acknowledgement}

The authors wish to thank Council of Scientific \& Industrial Research (CSIR), India to undertake the study under the STRAIT - XII Five Year Plan Network project. The authors would also like to thank the Director, Central Leather Research Institute (CLRI) India for permitting to publish this work.

\section{References}

Adroer, N., Casas, C., de Mas, C., \&Solà, C.
(1990). Mechanism of formaldehyde biodegradation by Pseudomonas putida. Applied microbiology and biotechnology, 33(2), 217-220.

Azachi, M., Henis, Y., Oren, A., Gurevich, P. and Sarig, S., Transformation ofFormaldehyde by a Halomonas sp. Canadian Journal of Microbiology 41: 548-553 (1995).

Bhalla, V., Grimm, P. C., Chertow, G. M., \&Pao, A. C. (2009). Melamine nephrotoxicity: an emerging epidemic in an era of globalization. Kidney international, 75(8), 774-779.

Bo, X., Maoxia, C., Zhouliang, T., Qinghua, L., Houzhen, Z., \&Xudong, L. (2015). Isolation and Characterization of Bacillus sp. BZ-001H Capable of Biodegrading Formaldehyde at High Concentration. Environmental Engineering Science, 32(9), 824-830.

Bozzi, A., Dhananjeyan, M., Guasaquillo, I., Parra, S., Pulgarin, C., Weins, C., \& Kiwi, J. (2004). Evolution of toxicity during melamine photocatalysis with TiO 2 suspensions. Journal of Photochemistry and Photobiology A: Chemistry, 162(1), 179-185.

Bradley, E. L., Boughtflower, V., Smith, T. L., Speck, D. R., \& Castle, L. (2005). Survey of the migration of melamine and formaldehyde from melamine food contact articles available on the UK market. Food additives and contaminants, 22(6), 597-606.

Cameron, S. M., K. Durchschein, J. E. Richman, M. J. Sadowsky, and L. P. 360 Wackett. 2011. A new family of biuret hydrolases functioning in striazinering 361 metabolism. ACS Catal. 2011: 1075-1082.

Cheng, G., Shapir, N., Sadowsky, M. J., $\&$ Wackett, L. P. (2005). Allophanate hydrolase, not urease, functions in bacterial cyanuric acid metabolism. Applied and 
environmental microbiology, 71(8), 4437-4445.

Chongcharoen, R., Smith, T. J., Flint, K. P., \& Dalton, H. (2005). Microbiology, 151, 2615-2622.

Cook, H.A., Klampfl, C.W., and Buchberger, W., Electrophoresis, 2005, vol. 26, p. 1576.

Di Maiuta, N., Hubschmid, S., Giuliani, N., Schwarzentruber, P., \& Dow, C. S. (2009). Microbial degradation of formaldehyde in white mineral dispersions preserved with formaldehyde-releasing biocides. International Biodeterioration \& Biodegradation, 63(6), 769-777.

Dobson, R. L., Motlagh, S., Quijano, M., Cambron, R. T., Baker, T. R., Pullen, A. M., \&Reimschuessel, R. (2008). Identification and characterization of toxicity of contaminants in pet food leading to an outbreak of renal toxicity in cats and dogs. Toxicological Sciences, 106(1), 251-262.

Eiroa, M., Kennes, C., \& Veiga, M. C. (2005). Simultaneous nitrification and formaldehyde biodegradation in an activated sludge unit. Bioresource technology, 96(17), 1914-1918.

El-Sayed, W. S., El-Baz, A. F., \& Othman, A. M. (2006). Biodegradation of melamine formaldehyde by Micrococcus sp. strain MF-1 isolated from aminoplastic wastewater effluent. International

biodeterioration \&

biodegradation, 57(2), 75-81.

Fruchey, I., N. Shapir, M. J. Sadowsky, and L. P. Wackett. 2003. On the origins of 387 cyanuric acid hydrolase: purification, substrates, and prevalence of AtzD from Pseudomonas sp. strain ADP. Appl. Environ. Microbiol. 69:3653-3657.

Glancer-Šoljan, M., \&Čačić, L. (2001). Aerobic degradation of formaldehyde in wastewater from the production of melamine resins. Food Technology and Biotechnology, 39(3), 197-202.

Gutheil, W. G., Kasimoglu, E., \& Nicholson, P. C. (1997). Induction of glutathione-dependent formaldehyde dehydrogenase activity in Escherichia coli and Hemophilus influenza. Biochemical and biophysical research communications, 238(3), 693696.

Halliwell, B. (1992). Reactive oxygen species and the central nervous system. In Free radicals in the brain (pp. 2140). Springer Berlin Heidelberg.

Hau, A. K. C., Kwan, T. H., \& Li, P. K. T. (2009). Melamine toxicity and the kidney. Journal of the American Society of Nephrology, 20(2), 245-250.

Kandelbauer, A., \&Widsten, P. (2009). Antibacterial melamine resin surfaces for wood-based furniture and flooring. Progress in organic coatings, 65(3), 305-313.

Kondo, T., Morikawa, Y., Hayashi, N., $\&$ Kitamoto, N. (2002). Purification and characterization of formate oxidase from a formaldehyde-resistant fungus. FEMS microbiology letters, 214(1), 137-142.

Lewis RJ, Sr; Hawley's Condensed Chemical Dictionary 14th ed. John Wiley \& Sons, Inc. New York, NY p. 703 (2001)

Li, Q., J. L. Seffernick, M. J. Sadowsky, and L. P. Wackett. 2009. Thermostable 401 cyanuric acid hydrolase from Moorellathermoacetica ATCC 39073. Appl. Environ.402 Microbiol. 75:69866991.

Lofrano, G., Meriç, S., Belgiorno, V., \& Napoli, R. M. (2007). Fenton's oxidation of various-based tanning materials. Desalination, 211(1), 10-21.

Lu, Z., \&Hegemann, W. (1998). Anaerobic toxicity and biodegradation of 
formaldehyde in batch cultures. Water Research, 32(1), 209-215.

Luo, J. J., Ding, J. F., Li, G. W., Zheng, T. L., \&Luo, Z. H. (2014). Characterization of a formaldehyde degrading fungus Penicilliumchrysogenum DY-F2 isolated from deep sea sediment. International Biodeterioration \& Biodegradation, 89 , 45-49.

Mirdamadi, S., Rajabi, A., Khalilzadeh, P., Norozian, D., Akbarzadeh, A., \&Mohseni, F. A. (2005). Isolation of bacteria able to metabolize high concentrations of formaldehyde. World Journal of Microbiology and Biotechnology, 21(6-7), 1299-1301.

Morikawa, Y., Hayashi, N., Kondo, T., \& Fukuda, N. (2013). Isolation and characteristics of a formaldehydedegrading fungus. Journal of chemical engineering of Japan, 46(5), 353-358.

Naviglio, B., Calvanese, G., Tortora, G., Cipollaro, L., Pierri, G., SPERIMENTALE, S., \& CONCIANTI, M. (2006). Characterisation of tannery chemicals: retanning agents. CUOIO PELLI MATERIE CONCIANTI, 82(2), 83.

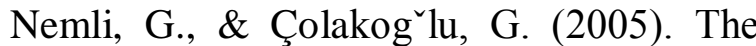
influence of lamination technique on the properties of particleboard. Building and Environment, 40(1), 8387.

Ping, L., Zhang, C., Zhang, C., Zhu, Y., He, H., Wu, M., \& Zhao, H. (2014). Isolation and characterization of pyrene and benzo [a] pyrene-degrading Klebsiella pneumoniae PL1 and its potential use in bioremediation. Applied microbiology and biotechnology, 98(8), 3819-3828.

Postgate JR (1998) Nitrogen fixation, 3rd edn. Cambridge University Press, Cambridge.
Saadoun, I. (2002). Isolation and characterization of bacteria from crude petroleum oil contaminated soil and their potential to degrade diesel fuel. Journal of basic microbiology, 42(6), $420-428$.

Salam, J. A., Lakshmi, V., Das, D., \& Das, N. (2013). Biodegradation of lindane using a novel yeast strain, Rhodotorula sp. VITJzN03 isolated from agricultural soil. World Journal of Microbiology and Biotechnology, 29(3), 475-487.

Sawada, A., Ikeda, R., Tamiya, E., Yoshida, T., Oyabu, T., \& Nanto, H. (2006). A novel formaldehyde-degrading fungus, Trichodermavirens: isolation and some properties. IEICE transactions on electronics, 89(12), 1786-1791.

Seffernick, J. L., A. G. Dodge, M. J. Sadowsky, J. A. Bumpus, and L. P. Wackett. (2010). Bacterial ammeline metabolism via guanine deaminase. J. Bacteriol. 196:1106-1112.

Seffernick, J. L., de Souza, M. L., Sadowsky, M. J., \&Wackett, L. P. (2001). Melamine deaminase and atrazine chlorohydrolase: 98 percent identical but functionally different. Journal of Bacteriology, 183(8), 24052410.

Seibert, C. M., \&Raushel, F. M. (2005). Structural and catalytic diversity within the amidohydrolase superfamily. Biochemistry, 44(17), 6383-6391.

Shelton, D. R., Karns, J. S., McCarty, G. W., \& Durham, D. R. (1997). Metabolism of Melamine by Klebsiella terragena. Applied and environmental microbiology, 63(7), 2832-2835.

Shinagawa, E., Toyama, H., Matsushita, K., Tuitemwong, P., Theeragool, G., \& Adachi, O. (2006). A novel type of formaldehyde-oxidizing enzyme from the membrane of Acetobacter sp. SKU 
14. Bioscience, biotechnology, and biochemistry, 70(4), 850-857.

Takagi, K., Fujii, K., Yamazaki, K. I., Harada, N., \& Iwasaki, A. (2012). Biodegradation of melamine and its hydroxy derivatives by a bacterial consortium containing a novel Nocardioides species. Applied microbiology and biotechnology, 94(6), 1647-1656.

Tian, Y., Chen, L., Gao, L., Michel, F. C., Keener, H. M., Klingman, M., \& Dick, W. A. (2012). Composting of waste paint sludge containing melamine resin and the compost's effect on vegetable growth and soil water quality.Journal of hazardous materials, 243, 28-36.

Vorholt, J. A. (2002). Cofactor-dependent pathways of formaldehyde oxidation in methylotrophic bacteria. Archives of microbiology, 178(4), 239-249.

Wackett, L., Sadowsky, M., Martinez, B., \&Shapir, N. (2002). Biodegradation of atrazine and related s-triazine compounds: from enzymes to field studies. Applied Microbiology and Biotechnology, 58(1), 39-45.

World Health Organization. WHO (2009). Toxicological and health aspects of melamine and cyanuric acid: report of a WHO expert meeting in collaboration with FAO, supported by Health
Canada, Ottawa, Canada, 1-4 December 2008.

Xin, H., \& Stone, R. (2008). Tainted milk scandal. Chinese probe unmasks hightech adulteration with melamine. Science (New York, $N Y$ ), 322(5906), 1310-1311.

Xu, Z., Wang, L., \&Hou, H. (2011). Formaldehyde removal by potted plant-soil systems. Journal of hazardous materials, 192(1), 314-318.

Yamazaki, T., Tsugawa, W., \&Sode, K. (2001, January). Biodegradation of formaldehyde by a formaldehyderesistant bacterium isolated from seawater. In Twenty-Second Symposium on Biotechnology for Fuels and Chemicals(pp. 213-217). Humana Press.

Yoshida, K., Ishii, H., Ishihara, Y., Saito, H., \& Okada, Y. (2009). Bioremediation potential of formaldehyde by the marine microalga Nannochloropsisoculata $\quad$ ST-3 strain. Applied biochemistry and biotechnology, 157(2), 321-328.

Yurimoto, H., Kato, N., \& Sakai, Y. (2005). Assimilation, dissimilation, and detoxification of formaldehyde, a central metabolic intermediate of methylotrophic metabolism. The Chemical Record, 5(6), 367-375.

\section{How to cite this article:}

Umamaheswari, B., and Rama Rajaram. 2016. Microaerobic Degradation of Melamine Formaldehyde Resin. Int.J.Curr.Microbiol.App.Sci.5(4): 904-917. doi: http://dx.doi.org/10.20546/ijcmas.2016.504.102 